\title{
Morbidity and health seeking behavior among the rural Population, Malaysia
}

\author{
Theingi Maung Maung', Sherly Deborah², Harini Narayanam³ ${ }^{3}$ Kevin Fernandez ${ }^{4}$, \\ Usha Kumari ${ }^{5}$ \\ ${ }^{1}$ Associate Professor, ${ }^{4}$ Professor, Unit of Community Medicine, ${ }^{2,3}$ Lecturer, ${ }^{5}$ Senior Associate Professor, Unit of \\ Physiology, Faculty of Medicine, AIMST University, Malaysia
}

Background: Health seeking behavior is defined as any deed that an individual tackles to perceive themselves to have a health issue or to be sick for the endeavor of discovering a suitable countermeasure. Delays in seeking health care are usually associated with an increase in the mortality rate and the perk of early treatment and control are also acknowledged. Aims and Objective: The present study aimed at finding the morbidity and health seeking behavior among the rural population, Malaysia. Materials and Methods: A community survey was carried out in the rural area of Kedah State and the sample size was 114. A structured questionnaire was used and the data were collected by face to face interview method. Results: Majority of the residents $(71.9 \%)$ were apparently healthy while $28.1 \%$ were diagnosed with illness. Top three common diseases were hypertension (53.1\%), diabetes $(34.4 \%)$ and heart disease $(6.3 \%)$. About $81.3 \%$ of them were taking their medications regularly whereas $18.7 \%$ were not compliant. Among those with illnesses, $31.3 \%$ of the respondents were using traditional medicine. About half of the respondents felt that they need not get check-ups and this becomes the major barrier to health care. It was followed by long wait, lack of doctors and mass media. The source of health information was mainly from health staff followed by mass media, friends and campaigns. Conclusion: Based on the study we can conclude that improving health literacy through intensive awareness campaigns and mass media and providing access to technology may create more health awareness and health consciousness in individuals and encourage them to lead a healthy lifestyle. Increasing the number of health care professionals and health care centers will motivate the individuals to monitor their diseases and treatment to improve the quality of life.

Key words: Morbidity; Health seeking behavior; Rural population; Malaysia
Access this article online

Website:

http://nepjol.info/index.php/AJMS

DOI: 10.3126/ajms.v11i3.27747

E-ISSN: 2091-0576

P-ISSN: 2467-9100

Copyright (c) 2020 Asian Journal of Medical Sciences

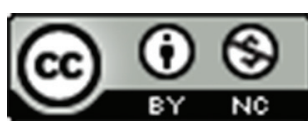

This work is licensed under a Creative Commons Attribution-NonCommercial 4.0 International License.

\section{INTRODUCTION}

In the recent trends, it is highly cataloged that seeking information and knowledge regarding one's health is increasing as an indispensable enduring approach to promote health and to accustom psychosocially to ailments.

A better perception of behavioral factors and developing strategies are mandatory that take healthcare-seeking behavior (HSB) into account.

A legitimate education of HSB has the power to decrease the delay in diagnosis, enhance treatment compliance and boost health promotion policies.
HSB is determined by various factors such as availability, accessibility, affordability, and acceptability of the service proficiencies to the health care seekers. ${ }^{2}$

Sara Mackian et al has reviewed the development of HSB as a tool for investigating the interaction of an individual/population with the health system which concluded that necessary actions has to be taken to compile the current dispersed theory about HSB so that it can be wholly portrayed.

Both morbidity and mortality patterns serves direction for the assortment of healthcare services needed. Hence, meticulous information on morbidity and mortality 
is obligatory in planning opportune intervention strategies. $^{3}$

In 2017, according to the Department of Statistics, Malaysia, the percentage of deaths caused by ischemic heart diseases, pneumonia, cerebrovascular diseases, transport accidents and malignant neoplasm (trachea, bronchus and lung) are 13.9\%, 12.7\%, 7.1\%, 4.6\% and $2.3 \%$ respectively. Among the above mentioned, ischemic heart diseases presents to be the cardinal cause of death in Malaysia and has added on $54 \%$ as compared to the year $2007 .^{4}$

Awareness through health education programs should be created among the public regarding medical assistance and to provide education about the proper use of nonprescription medicines that are usually taken for treating minor illnesses.

The public also needs to be motivated to seek medical assistance to restraint their health and make right decisions about health problems.

Therefore the present study aimed at finding the morbidity and health seeking behavior among the rural population, Malaysia.

\section{MATERIALS AND METHODS}

A cross-sectional study was carried out in the rural area of Kedah state which is in the northern part of Malaysia. Sample population was 114 and study was carried out as Community Survey Project by medical students. Both gender and all ages were included in the study and those who were critically ill and those who didn't give consent were not considered. It was a household survey using structured questionnaire. Information was gathered by face to face interview method.

\section{Ethical consideration}

Community based survey was carried out after getting the approval from University Ethical Approval Committee. Informed consent was taken from all the respondents and the personal data were kept confidentially.

\section{Statistical analysis}

Data entry and analysis were done by the SPSS version 22 and relevant tables were used to convey the information.

\section{RESULTS}

The social demographic background of the participants is depicted in Table 1.

\begin{tabular}{|c|c|c|c|}
\hline $\begin{array}{l}\text { Demographic } \\
\text { Variable }\end{array}$ & Categories & $\mathbf{N}(\%)$ & Total \\
\hline Age group & $\begin{array}{l}\text { Less than } 40 \text { years } \\
\text { old } \\
\text { More than } 40 \text { years } \\
\text { old }\end{array}$ & $\begin{array}{l}48(42.1) \\
66(57.9)\end{array}$ & 114 \\
\hline Gender & $\begin{array}{l}\text { Male } \\
\text { Female }\end{array}$ & $\begin{array}{l}62(54.4) \\
52(45.6)\end{array}$ & 114 \\
\hline Race & $\begin{array}{l}\text { Malay } \\
\text { Chinese }\end{array}$ & $\begin{array}{c}109 \\
(95.6) \\
5(4.4)\end{array}$ & 114 \\
\hline Religion & $\begin{array}{l}\text { Islam } \\
\text { Buddha }\end{array}$ & $\begin{array}{c}111 \\
(97.4) \\
3(2.6)\end{array}$ & 114 \\
\hline Marital Status & $\begin{array}{l}\text { Single } \\
\text { Married } \\
\text { Divorced } \\
\text { Widow } \\
\text { Widower }\end{array}$ & $\begin{array}{c}31(27.2) \\
76(66.7) \\
1(0.9) \\
5(4.4) \\
1(0.9)\end{array}$ & 114 \\
\hline Occupation & $\begin{array}{l}\text { Unemployed } \\
\text { Employed } \\
\text { Housewife } \\
\text { Student }\end{array}$ & $\begin{array}{l}36(31.6) \\
50(43.9) \\
14(12.3) \\
14(12.3)\end{array}$ & 114 \\
\hline $\begin{array}{l}\text { Education } \\
\text { level }\end{array}$ & $\begin{array}{l}\text { Primary } \\
\text { Secondary } \\
\text { Tertiary } \\
\text { College } \\
\text { Can read/write }\end{array}$ & $\begin{array}{c}40(35.1) \\
62(54.4) \\
6(5.3) \\
3(2.6) \\
3(2.6)\end{array}$ & 114 \\
\hline Type of family & $\begin{array}{l}\text { Nuclear } \\
\text { Extended } \\
\text { Single parent } \\
\text { Others }\end{array}$ & $\begin{array}{c}69(60.5) \\
37(32.5) \\
5(4.4) \\
3(2.6)\end{array}$ & 114 \\
\hline $\begin{array}{l}\text { Total income } \\
\text { per month }\end{array}$ & $\begin{array}{l}\text { Less than RM } 1000 \\
\text { RM } 1001-2000 \\
\text { RM 2001-3000 } \\
\text { RM } 3001-4000 \\
\text { RM } 4001-5000\end{array}$ & $\begin{array}{c}66(57.9) \\
35(30.7) \\
11(9.6) \\
1(0.9) \\
1(0.9)\end{array}$ & 114 \\
\hline
\end{tabular}

Number of respondents and their age

Totally 114 participants were involved in the study and majority of them were more than 40 years old which accounts for $57.9 \%$. On the other hand, $42.1 \%$ of the respondents were lesser or equal to 40 years old. 62 males $(54.4 \%)$ and 52 females $(44.6 \%)$ were involved in the study.

\section{Ethnicity}

Out of the 114 respondents, $109(95.6 \%)$ of them were Malays and the remaining $5(4.4 \%)$ were Chinese. In addition, $111(97.4 \%)$ respondents were Islam whereas only $3(2.6 \%)$ respondents were Buddhist.

\section{Marital status}

Most of them were married: 76 respondents to be exact, giving a percentage of $66.7 \%$;; $31(27.2 \%)$ were single; $5(4.4 \%)$ being a widow and respondents who had been divorced and being a widower carry an equal percentage of $0.9 \%$.

\section{Employment rate}

The employment rate $(43.9 \%)$ for residents is higher compared to the unemployment rate $(31 \%)$. The number

Asian Journal of Medical Sciences | May-Jun 2020 | Vol 11 | Issue 3 
of housewives and students were the same, which is 14 in each, both accounting to a percentage of $12.3 \%$.

\section{Literacy}

Education level wise, respondents have a high percentage $(54.4 \%)$ of attaining secondary education. Number of respondents who attained primary education comes second, which were 40 in number $(35.1 \%)$. There were only $6(5.3 \%)$ respondents who attended tertiary education. Out of the remaining 6 respondents, $3(2.6 \%)$ of them attended college and another $3(2.6 \%)$ were only able to read or write. This result shows that nuclear family is the most common type (60.5\%) in the study area. Based on the respondents' income, majority of the respondents $(57.9 \%)$ earn less than RM 1000 per month.

The morbidity pattern and duration of illness among participants is laid down in Table 2.

Majority of the residents in the rural area $(71.9 \%)$ were apparently healthy while $28.1 \%$ were diagnosed with illness. Among the illnesses, hypertension (53.1\%) was most common followed by diabetes (34.4\%) and heart disease $(6.3 \%)$. The longest duration of illness among the population with illness was more than 5 years with $87.5 \%$. It is followed by $9.4 \%$ of 1 to 5 years disease duration.

The health seeking pattern among participants is depicted in Table 3.

Out of 114 participants, 32 participants were diagnosed with some kind of diseasesas shown in table 3 which is based on this population. Majority $(93 \%)$ of them were on treatment and $59.4 \%$ had known family history of medical illnesses. Approximately half of them (59.4\%) made the decision of consulting treatment by themselves; about $28.1 \%$ listen to their spouses and $12.5 \%$ to their children. Out of 32 participants, 21(65.6\%) usually seek their treatment alone. In this study, majority (90.6\%) usually seek treatment in the government health clinics whereas $6.3 \%$ visit pharmacy. About $81.3 \%$ of them were taking their medications regularly whereas $6(18.7 \%)$ were not compliant. In regards with traditional medicine, $31.3 \%$ of the respondents were using it whereas $68.8 \%$ are not on any traditional medicine. Among 32, 19(59.4\%) had adequate financial support whereas $13(40.6 \%)$ had financial difficulties for the treatment. In this study, $81.3 \%$ of them use car as a transport to health care facilities while $18.7 \%$ use motorcycle.

The barrier to health seeking and source of health information among participants is mentioned in Table 4.

Among the entire population, $47.4 \%$ had undergone a medical check-up and 52.6\% had never gone for it. About

\begin{tabular}{|c|c|c|c|}
\hline $\begin{array}{l}\text { Morbidity } \\
\text { Variables }\end{array}$ & Categories & N (\%) & Total \\
\hline \multirow{3}{*}{$\begin{array}{l}\text { Diagnosed with any } \\
\text { illness/illnesses } \\
\text { Type of illness }\end{array}$} & Yes & $32(28.1)$ & \multirow[t]{2}{*}{114} \\
\hline & No & $82(71.9)$ & \\
\hline & Diabetes & $11(34.4)$ & \multirow[t]{4}{*}{32} \\
\hline & Hypertension & $17(53.1)$ & \\
\hline & Heart disease & $2(6.3)$ & \\
\hline & Others & $2(6.3)$ & \\
\hline \multirow{3}{*}{$\begin{array}{l}\text { Longest duration of } \\
\text { your illness }\end{array}$} & Less than 1 year & $1(3.1)$ & \multirow[t]{3}{*}{32} \\
\hline & $1-5$ years & $3(9.4)$ & \\
\hline & $\begin{array}{l}\text { More than } 5 \\
\text { years }\end{array}$ & $28(87.5)$ & \\
\hline
\end{tabular}

\begin{tabular}{llcc}
\multicolumn{4}{l}{ Table 3: Health seeking pattern among the } \\
participants with diseases \\
Variables & Categories & N (\%) & Total \\
\hline Any treatment before & Yes & $30(93.8)$ & 32 \\
& No & $2(6.3)$ & \\
Family history of & Yes & $14(59.4)$ & 32 \\
medical illness & No & $18(40.6)$ & \\
Whom do you consult & You & $19(59.4)$ & 32 \\
before making & Spouse & $9(28.1)$ & \\
decision to seek for & Children & $4(12.5)$ & \\
treatment & Parents & $0(0.0)$ & \\
& Others & $0(0.0)$ & \\
Usually seek & Yes & $21(65.6)$ & 32 \\
treatment alone & No & $11(34.4)$ & \\
Healthcare seeking & Government & $29(90.6)$ & 32 \\
place & Clinic/Hospital & $2(6.3)$ & \\
& Pharmacy & $0(0.0)$ & \\
& Homeopathy & $0(0.0)$ & \\
& Faith Leader & $1(3.1)$ & \\
Takes medicine & Others & & \\
regularly & Yes & $26(81.3)$ & 32 \\
Any traditional & No & $6(18.7)$ & \\
medicine & Yes & $10(31.3)$ & 32 \\
Adequate financial & No & $22(68.8)$ & \\
support & Yes & $19(59.4)$ & 32 \\
Transport used & No & $13(40.6)$ & \\
& Car & $26(81.3)$ & 32 \\
& Motorcycle & $6(18.7)$ & \\
& Bus & $0(0.0)$ & \\
& Taxi & $0(0.0)$ & \\
\hline & Others & $0(0.0)$ & \\
& & & \\
& & &
\end{tabular}

\begin{tabular}{|c|c|c|c|}
\hline Variables & Categories & N (\%) & Total \\
\hline $\begin{array}{l}\text { Undergone } \\
\text { check-up before }\end{array}$ & $\begin{array}{l}\text { Yes } \\
\text { No }\end{array}$ & $\begin{array}{l}54(47.4) \\
60(52.6)\end{array}$ & 114 \\
\hline $\begin{array}{l}\text { Barriers to } \\
\text { health seeking }\end{array}$ & $\begin{array}{l}\text { Feel the need not to } \\
\text { Long wait } \\
\text { Lack of doctors } \\
\text { Mass media }\end{array}$ & $\begin{array}{c}59(51.8) \\
45(39.5) \\
4(3.5) \\
6(5.3)\end{array}$ & 114 \\
\hline $\begin{array}{l}\text { Source } \\
\text { of health } \\
\text { information }\end{array}$ & $\begin{array}{l}\text { Health staff } \\
\text { Mass media } \\
\text { Friends } \\
\text { Campaign } \\
\text { Others }\end{array}$ & $\begin{array}{c}52(45.6) \\
29(25.4) \\
23(20.2) \\
9(7.9) \\
1(0.9)\end{array}$ & 114 \\
\hline
\end{tabular}


$51.8 \%$ feel that they need not get check-ups and this becomes the major barrier to health care. It was followed by long wait $(39.5 \%)$, lack of doctors $(3.5 \%)$ and mass media $(5.3 \%)$. The source of health information is mainly from health staff with $45.6 \%$, followed by mass media with $25.4 \%$, friends with $20.2 \%$ and campaigns with $7.9 \%$.

\section{DISCUSSION}

The current survey was conducted amongst rural population of Malaysia. The participants include males and females of different socioeconomic and educational backgrounds. Majority of the participants are Malay with secondary education and employment. Most of them belong to low income group earning below RM 1000 per month, married and living in a nuclear family.

In the current survey, out of 114 respondents only 32 of them have health related issues while the majority (82) of them are apparently healthy. Hypertension was reported to be of highest prevalence followed by diabetes mellitus and other heart diseases. Most of them have been enduring the illness for more than 5 years.

It is a welcoming trend to see that there was an increasing tendency of population to seek treatment from healthcare providers and pharmacists in dealing with their illnesses. Majority of them are seeking treatment in government health clinics.

It has been observed that socio-economic status (SES) of the population like household income, level of education were the main factors for visiting government health facilities. Some of the respondents have reported that they do not have enough financial support to address their health issues. Lack of financial support could be one of the reasons for the increasing popularity of traditional medication systems, as some of the respondents use traditional medicines to cure their illness. Previous research have shown that health care utilization is determined by three types of factors namely predisposing traits, which include demographic, social and attitude/belief; enabling characteristics such as income, insurance and accessibility to a regular source of care. ${ }^{5}$ This survey revealed that more people from the lower SES groups visited government health facilities for treatment of their chronic illnesses.

Majority of the respondents decided for themselves if health care is needed or not, followed by spouse at the second place. As majority of the respondents independently decided the need for care, equipping them with adequate health related knowledge will help them make better decisions for themselves and for other family members as well. By providing more appropriate and interactive platforms to gain health-related knowledge, individuals who are now slightly more inclined towards self-decision on own healthcare needs can be empowered. ${ }^{6}$

Access to health care services is critical to good health, yet rural residents face a variety of access barriers. It was not surprising that a little more than half of the population employed in the study has never done a health checkup. The major barrier identified was that individuals did not feel the need for a checkup. This attitude can be attributed to minimum education or poor health literacy, location of the villages, inaccessibility to emerging technologies like mobile phones, use of internet, inability to afford medical care etc. ${ }^{7}$

The second barrier in the survey is difficulty in getting timely appointments with doctors. A shortage of health care professionals in the rural areas limits the access to healthcare. With few doctors and medical professionals accepting rural postings, the patient-doctor ratio cannot be matched, resulting in long wait for appointments. As most of them fall in the low-income category, uninsured rural residents face greater difficulty accessing care due to the limited supply of rural healthcare providers who offer low-cost or charity healthcare, when compared to their urban counterparts.

Health literacy is a crucial factor in health and well-being. ${ }^{8}$ Health literacy is defined as "the degree to which individuals have the capacity to obtain, process, and understand basic health information and services needed to make appropriate health decisions" and it is vital to "opening doors to health and wellbeing".. Limited health information has been shown to be related to lower health status, negative health outcomes, higher healthcare costs, and lower quality of care. ${ }^{10}$ The outcome of the study revealed that the most common sources of health information seeking among rural community members in the district of investigation are, health care providers, mass media, friends and campaigns.

\section{CONCLUSION}

Socio-economic status, poor education, limited health information and availability of health care have been identified as the major reasons contributing to the morbidity rates in the rural community. We recommend that strategies for improving health information and reducing barriers to obtaining health-related information should be designed. Health literacy must be improved as low health literacy can make residents hesitant to seek healthcare due to fear of communicating with a healthcare professional. Education on how to access health information through 
other sources for free or at low cost, including books, magazines, health lectures, and health fairs, needs to be provided. Such education might contribute to decreasing economic burden, improving health literacy, and relieving health disparities, particularly for individuals with limited or inadequate health information in rural communities.

More primary care centers must be provided at the rural communities, to address the shortage of doctors and other health care professionals. These centers provide health promotion, disease prevention, health maintenance, counseling, patient education, diagnosis and treatment of acute and chronic illnesses in a variety of health care settings.

\section{REFERENCES}

1. Mackian S, Bedri N and Lovel H. Up the garden path and over the edge: where might health-seeking behaviour take us? Health policy and planning 2004;19(3):137-146.

https://doi.org/10.1093/heapol/czh017

2. Atwine $\mathrm{F}$ and Hjelm K. Health professionals' knowledge and attitudes to healthcare-seeking practices and complementary alternative medicine usage in Ugandans with diabetes: a crosssectional survey. Pan African Medical Journal 2017;28(1). https://doi.org/10.11604/pamj.2017.28.256.11615

3. Karim HA. The elderly in Malaysia: demographic trends. Medical
Journal of Malaysia 1997;52:206-212.

4. Department of Statistics, Malaysia, Official Portal. [Statistics on Causes of Death, Malaysia, 2017] [2017] Available from: URL: https://www.dosm.gov.my/v1/index.php?r=column/ cthemeByCat\&cat $=401 \&$ bul_id $=Y 3 p s Y U I 2 V j U 0 Z z R h Z U 1 \mathrm{kcVF}$ MMThGUT09\&menu id=LOpheU43NWJwRWVSZkIWdzQ4TIh UUT09

5. Amal NM, Paramesarvathy R, Tee GH, Gurpreet $\mathrm{K}$ and Karuthan C. Prevalence of Chronic Illness and Health Seeking Behaviour in Malaysian Population: Results from the Third National Health Morbidity Survey (NHMS III) 2006. The Medical journal of Malaysia 2011; 66(1):36-41.

6. Taffa $\mathrm{N}$ and Chepngeno $\mathrm{G}$. Determinants of health care seeking for childhood illnesses in Nairobi slums. Tropical Medicine \& International Health 2005;10(3):240-245. https://doi.org/10.1111/j.1365-3156.2004.01381.x

7. Sokey PP and Adisah-Atta I. Challenges Confronting Rural Dwellers in Accessing Health Information in Ghana: Shai Osudoku District in Perspective. Social Sciences 2017; 6(2):66. https://doi.org/10.3390/socsci6020066

8. Weinstein RS and Lopez AM. Health literacy and connected health. Health Affairs 2014;33(6):1103B. https://doi.org/10.1377/hlthaff.2014.0396

9. U.S. Department of Health and Human Services. [Healthy People 2020] [2011] Available from: URL: http://www. healthypeople. gov/2020/about/default.aspx

10. Rimal RN and Lapinski MK. Why health communication is important in public health. Bulletin of the World Health Organization 2009;87:247-a.

https://doi.org/10.2471/BLT.08.056713

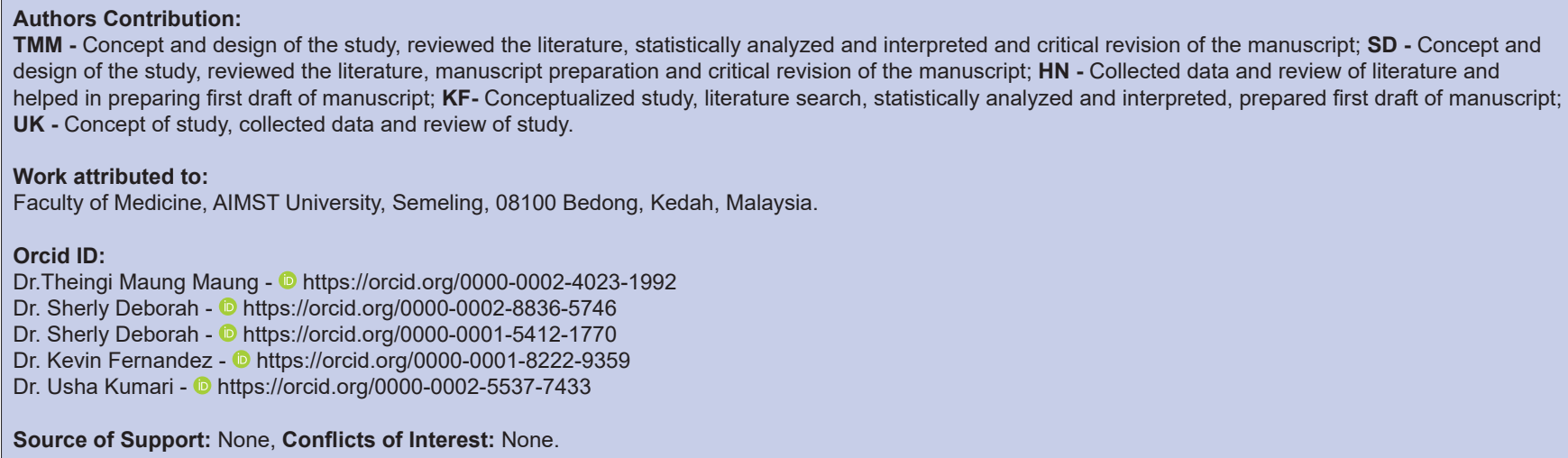

